\title{
Del Estado comunicador al Estado de los medios. Catorce años de hegemonía comunicacional en Venezuela
}

\section{Agrivalca Ramsenia Canelón-Silva ${ }^{1}$}

Recibido: 2014-09-02

Enviado a pares: 2014-09-03

DOI: 10.5294/pacla.2014.17.4.11
Aprobado por pares: 2014-09-15

Aceptado: 2014-10-06

\section{Para citar este artículo / To reference this article / Para citar este artigo}

Canelón-Silva, A. R. Diciembre de 2014. Del Estado comunicador al estado de los medios. Catorce años de hegemonía comunicacional en Venezuela. Palabra Clave 17(4), 12431278. DOI: 10.5294/pacla.2014.17.4.11

\section{Resumen}

El presente artículo tiene como finalidad exponer una suerte de cartografía que dé cuenta del estado de los medios de comunicación social en Venezuela con base en la retrospectiva de la última década, en la ruta de calibrar la incidencia que, sobre la estructura de medios, tuvieron las políticas públicas de comunicación formuladas y ejecutadas por el Gobierno Bolivariano durante la administración del presidente Hugo Chávez -todavía vigentes-, poniendo el acento sobre los cambios legales registrados en el área durante el período, la relación de los medios de propiedad privada con las instancias de poder, el papel jugado por los medios en manos del Estado, la densidad de los medios alternativos-comunitarios y, a trazos gruesos, la composición de las plataformas mediáticas públicas y privadas de prensa, radio y televisión.

\section{Palabras clave}

Medios de comunicación, políticas públicas de comunicación, concentración de medios, hegemonía comunicacional. (Fuente: Tesauro de la Unesco).

1 Universidad de La Sabana, Magíster en Comunicación Social, Colombia. agrivalca.canelon@unisabana.edu.co 


\section{From the Newscaster State to the State of The Media. 14 Years of Communicational Hegemony in Venezuela}

\section{Abstract}

This article aims to present a kind of mapping that accounts for the state of the social communications media in Venezuela based on the retrospective of the last decade, on route to gauging the impact which the public communication policies had on the structure of the media, as formulated and implemented by the Bolivarian Government during the administration of President Hugo Chavez, and which are still in place, with emphasis on legal changes recorded in this area during the period. Also, the relationship of the private media companies with the instances of power, the role played by the media in the hands of the State, the density of the alternativecommunity media and, in broad terms, the composition of the public and private media platforms of press, radio and television.

\section{Keywords}

Communications media, public policies on communications, media concentration, communicational hegemony. (Source: Unesco Thesaurus). 


\section{Do estado-comunicador ao estado dos meios de comunicação. 14 Anos de hegemonia comunicacional na Venezuela}

\section{Resumo}

O presente artigo tem como finalidade expor uma espécie de mapeamento que represente o estado dos meios de comunicação social na Venezuela com base na retrospectiva da última década, com o objetivo de avaliar o impacto que, sobre a estrutura dos meios de comunicação, tiveram as políticas públicas de comunicação formuladas e executadas pelo Governo Bolivariano durante a administração do presidente Hugo Chávez -ainda vigentes-, com ênfase nas mudanças legais registradas na área durante o período, a relação dos meios de propriedade privada com as instâncias de poder, o papel desempenhado pelos meios de comunicação nas mãos do Estado, a densidade dos meios de comunicação alternativos-comunitários e, grosso modo, a composição das plataformas mediáticas públicas e privadas de imprensa, rádio e televisão.

\section{Palavras-chave}

Meios de comunicação, políticas públicas de comunicação, concentração dos meios de comunicação, hegemonia comunicacional. (Fonte: Tesauro da Unesco). 


\section{Introducción}

De entrada, a riesgo de incurrir en una perogrullada, pertinente será puntualizar que, en el último lustro, el sistema de medios de comunicación en Venezuela cambió a consecuencia de la vorágine política que condujo al Estado y a un buen contingente de los órganos de difusión privados a asumir un papel activo al calor de la polarización del país.

No en vano, acogiéndose a lo apuntado por Gómez (2013, p. 49), desde su llegada al poder el gobierno del Movimiento Quinta República (MVR), devenido hoy en Partido Socialista Unido de Venezuela (PSUV), consagró el grueso de sus energías a la consecución de tres objetivos básicos en materia comunicacional, a saber: 1) el levantamiento de un marco regulatorio único que rigiera a todos los medios audiovisuales y electrónicos; 2) la ampliación de los medios alternativos-comunitarios, lo mismo que los públicos, antecedida por una fuerte inversión económica con el fin de optimizar el funcionamiento de estos aparatos mediáticos a través de la capacitación, la dotación de equipos y el mejoramiento de la infraestructura, y3) la creación de organismos independientes que centralicen el control de contenidos, el acceso a las subvenciones y las frecuencias y el manejo de los cursos formativos, entre otras cuestiones.

A no dudar, semejantes declaraciones no pueden apreciarse en su justa dimensión al abandono del doble rol desempeñado por el Estado en el escenario mediático como regulador y operador, sin descontar su relación con el sector privado y los medios alternativos-comunitarios. De allí que, en aras de describir las transformaciones acarreadas por las políticas públicas de comunicación aplicadas por el gobierno bolivariano desde 1999 hasta el presente, se consentirá en un breve ejercicio documental enfilado a brindar el estado de la cuestión en Venezuela partiendo del deslinde de la línea de pensamiento que inspira y encauza el accionar del Estado venezolano en el terreno comunicacional, para exponer más tarde las coordenadas actuales de los medios de propiedad privada y de propiedad pública con énfasis en la prensa, la radio y la televisión, dejando hacia el final el abordaje de la situación de los medios alternativos-comunitarios y las conclusiones. 


\section{Marco político: hegemonía comunicacional}

En el intento por retratar con una visión panorámica aunque sucinta, inclusive para algunos excesivamente simplificada, el devenir de los medios de comunicación social en Venezuela aparejado al proceso político registrado en el país durante la segunda mitad del siglo XX, bien cabe tomar en préstamo la divisoria propuesta por el periodista y profesor universitario Javier Conde (2014, p. 7), quien identifica, cuando menos, cuatro tramos históricos que se extienden desde el 23 de enero de 1958 hasta nuestros días.

Así las cosas, el periplo inicia en las postrimerías de la década de los cincuenta con la caída de la dictadura del general Marcos Pérez Jiménez y la consiguiente instauración del régimen democrático al amparo del "Sistema Populista de Conciliación de Élites” (Rey, 1989), prolongándose esta etapa hasta mediar el año 1973, momento en el que concluye el primer periodo de gestión gubernativa de Rafael Caldera al fragor de unos precios del petróleo in crescendo. En este encuadre, correspondió a los medios de comunicación social investidos de una influencia cada vez más amplia en los ámbitos político, económico, social y cultural, desempeñar un rol estelar en la asunción y la consolidación del modelo democrático en Venezuela, haciendo causa común con la clase dirigente ante la embestida encabezada por los intentos golpistas de derecha y los alzamientos armados de izquierda que, inspirados en la Revolución cubana, plagaban la escena latinoamericana de entonces. Fue la hora del florecimiento de los medios impresos, lo mismo que de los radiofónicos, y se perfilaron como connaturales a las nuevas reglas del modus vivendi político tanto la libertad de expresión como el acceso a la información pública.

Poco faltaría, empero, para que este "estado de armonía” con las instancias oficiales se viera quebrantado, si acaso no roto, no más avanzar los años circunscritos entre 1973 y 1988, fase en la que, de hecho, empezaron a vislumbrarse los síntomas de desgaste del sistema democrático venezolano en el contexto de una sociedad eminentemente bipartidista, aquejada por el declive de los niveles de bienestar sustentados en la bonanza petrolera, la crisis de la deuda externa, los márgenes de pobreza, los índices de inseguridad personal y los escándalos por corrupción administrativa. De allí 
que los medios de comunicación social, presagiando su transmutación de "mediadores de información" a "mediadores políticos", pasaron a convertirse en el receptáculo de los reclamos y las aspiraciones del colectivo de cara a una institucionalidad socavada y unos liderazgos erosionados en términos de credibilidad, amén de unas organizaciones sindicales y gremiales disminuidas en su capacidad de convocatoria y militancia.

Precisamente, semejantes condiciones constituyeron el caldo de cultivo que signó el ciclo experimentado de 1988 a 1998, en el que los medios de comunicación social se erigieron como actores políticos privilegiados con ascendencia sobre la ciudadanía, reforzando frente al establishment un talante cuestionador, rayano en la antipolítica, en especial después de acaecidas las asonadas militares del 4 de febrero y del 27 de noviembre de 1992.

Por lo demás, a la luz de esta antesala, de por sí cargada de tensiones y desencuentros, no es para nada fortuito que, con el ascenso de Hugo Chávez a la presidencia de Venezuela el 2 de febrero de 1999, y a pocos meses de comenzar su gobierno prendido a la promesa de refundar la República de la mano de la Revolución bolivariana, sobreviniera una redefinición radical de la relación del sistema de medios de comunicación de masas con la esfera del poder político y, más allá, con el propio Estado en calidad de agente interventor y regulador de la sociedad, dando lugar a lo que Bisbal (2009) ha consentido en llamar el Estado comunicador y, bajo su égida, la configuración de una política pública de comunicación acoplada a los requerimientos de intermediación simbólica del Gobierno.

No en balde, luego de los eventos ocurridos en Venezuela en el mes de abril de 2002 que implicaron el rompimiento del hilo constitucional, y en el trayecto hacia el año 2003 con el paro cívico nacional, la administración del hoy finado presidente Hugo Chávez inauguró una nueva época que sería proclamada en definitiva el 8 de enero de 2007 apelando al rótulo de "hegemonía comunicacional e informativa del Estado". Por aquel entonces, Andrés Izarra, director del canal Telesur y exministro del Poder Popular para la Comunicación y la Información (Minci), lo expresaría con estas palabras 
Para el nuevo panorama estratégico que se plantea, la lucha que cae en el campo ideológico tiene que ver con una batalla de ideas por el corazón y la mente de la gente. Hay que elaborar un nuevo plan, y el que nosotros proponemos es que sea hacia la hegemonía comunicacional e informativa del Estado [...] Nuestro socialismo necesita una hegemonía comunicacional [...] todas las comunicaciones tienen que depender del Estado como bien público (Weffer, 2007, 8 de enero).

Atendiendo a este desiderátum, a los ojos de las entidades gubernamentales el sector de las comunicaciones masivas, y en singular los medios radioeléctricos, redoblaron su ribete estratégico en tanto "trincheras" consagradas a los fines del aparato político, léase el modelaje cultural y la confrontación ideológica. Y es que, si se examina a pie juntillas lo que Hugo Chávez acunó como la "Comunicación Revolucionaria del Socialismo del Siglo XXI", ineludible es traer a colación tres aspectos medulares que han acompañado los derroteros del proyecto político bolivariano, modificando, de suyo, la estructura del ecosistema comunicacional imperante en Venezuela hasta finales de la década de los noventa, a saber:

1. La elaboración de un marco regulatorio destinado a normalizar en su totalidad, y por primera vez en 60 años, el área de las telecomunicaciones en el país, ostentando como bastiones la Ley Orgánica de Telecomunicaciones (Lotel, 2000) y la Ley de Responsabilidad Social de Radio y Televisión (Ley Resorte, 2004).

2. El incremento de la fiscalización a los medios de comunicación de gestión privada, aunado a la adquisición de órganos de difusión pertenecientes a este bloque, demarcando una política de quiebre paulatino de la concentración de propiedad.

3. La integración de una plataforma de medios públicos, secundada por el auspicio a la comunicación alternativa y la producción independiente (Gómez, 2013, p. 39).

Aclaratorias sean hechas: el diseño de estos lineamientos y la progresión de su ejecución en el tiempo responden, en mucho, a los enunciados plasmados en tres documentos clave de más largo aliento, nucleados en torno a la planificación global de las políticas públicas orientadoras de 
las distintas parcelas de la vida nacional en la senda hacia la construcción del socialismo del siglo XXI.

En este sentido, menester es citar, de entrada, el texto titulado "La nueva etapa, el nuevo mapa estratégico", cuyo resumen, publicado por la Presidencia de la República Bolivariana de Venezuela el 17 de noviembre de 2004 tras celebrarse el "Taller de Alto Nivel” dictado por Hugo Chávez a los personeros del Gobierno bolivariano los días 12 y 13 de noviembre, da cuenta, en el trazado de los "Diez Grandes Objetivos Estratégicos", del mandato n. ${ }^{\circ}$, "Articular y optimizar la nueva estrategia comunicacional", desagregado tal como se expone a continuación.

Siguiendo el orden cronológico, el segundo documento maestro en el que se esbozan directrices atinentes al fuero comunicacional remite al "Plan Nacional de Desarrollo Económico y Social 2007-2013", también conocido como el "Proyecto Nacional Simón Bolívar 2007-2013" o el "Primer Plan Socialista 2007-2013", donde se le concede espacio al tópico mediático hacia la parte final del capítulo III, "Democracia protagónica revolucionaria", específicamente en el apartado "Estrategias y políticas":

III-3.9. Fomentar la utilización de los medios de comunicación como instrumentos de formación.

III-3.9.1. Utilizar los medios de comunicación como instrumentos de formación en valores ciudadanos.

III-3.9.2. Educar en la utilización responsable y crítica de los medios de comunicación.

III-3.9.3. Promover el control social de la población sobre los medios de comunicación masivos.

III-3.10. Promover el equilibrio entre los deberes y derechos informativos y comunicacionales de los ciudadanos y las ciudadanas.

III-3.10.1. Facilitar el acceso de la población excluida a los medios de comunicación. 


\section{Cuadro 1 \\ La nueva etapa, el nuevo mapa estratégico \\ Objetivo Estratégico $n .{ }^{0} 2$. Articular y optimizar la nueva estrategia comunicacional}

\begin{tabular}{|c|c|}
\hline & Herramientas \\
\hline 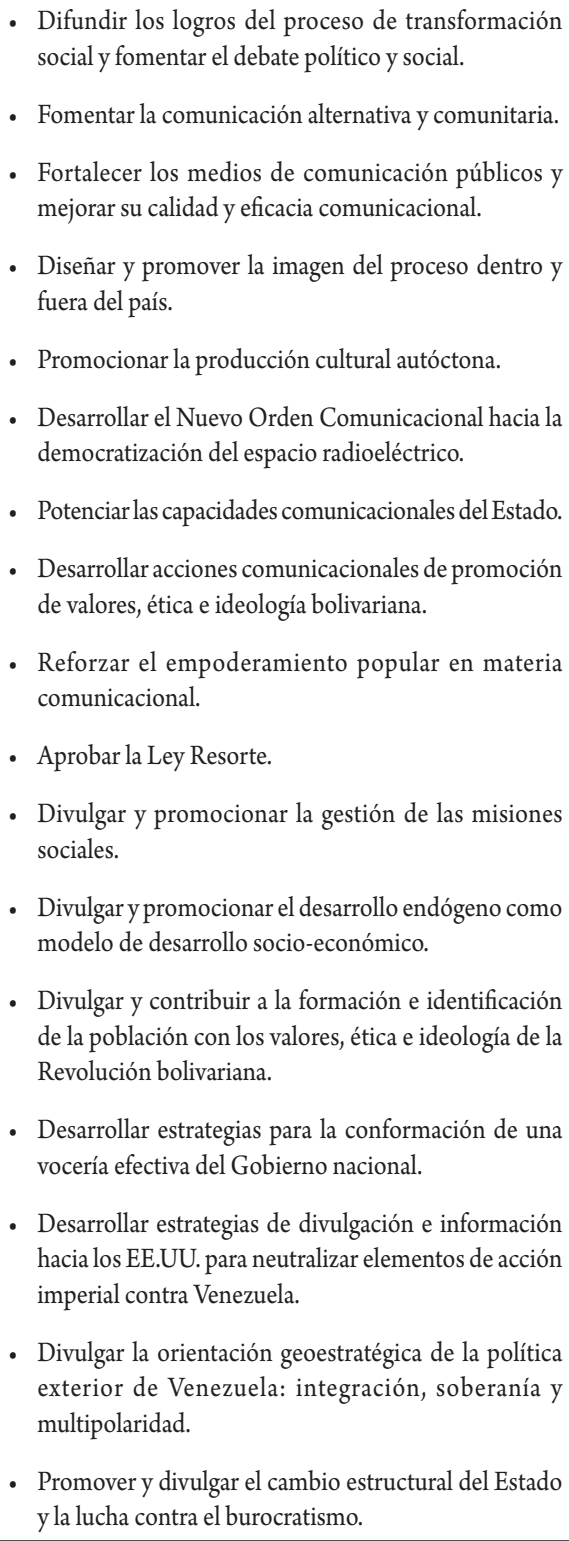 & 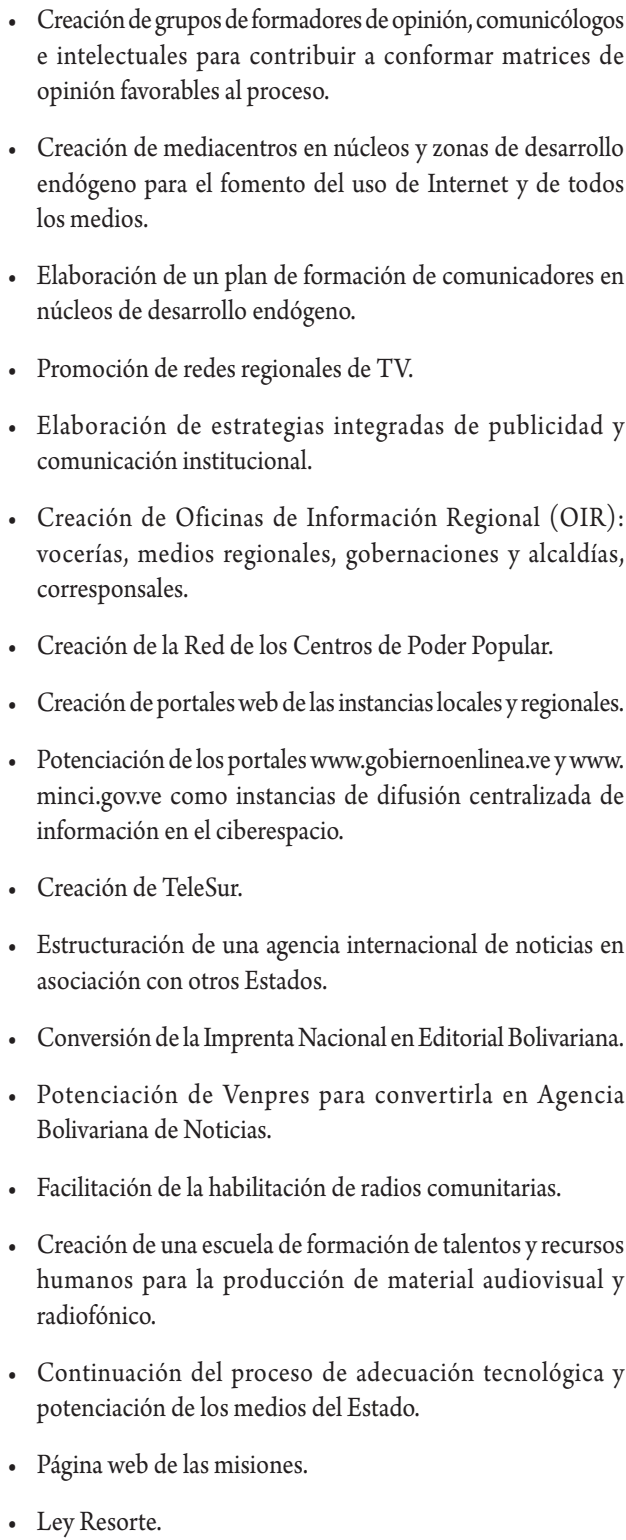 \\
\hline
\end{tabular}

Fuente: Presidencia de la República Bolivariana de Venezuela (2004, pp. 4-5). 
III-3.10.2. Estimular la participación ciudadana en la defensa de sus derechos y el cumplimiento de sus deberes comunicacionales.

III-3.11. Universalizar el acceso a los diferentes tipos de comunicación.

III-3.11.1. Fomentar el hábito de la lectura, el uso responsable de Internet y otras formas informáticas de comunicación e información.

III-3.11.2. Facilitar el acceso de las comunidades a los medios de comunicación.

III-3.11.3. Facilitar condiciones tecnológicas, educativas y financieras a los nuevos emprendedores comunicacionales.

III-3.11.4. Establecer como obligatorio la utilización de códigos especiales de comunicación para los discapacitados.

III-3.11.5. Fortalecer los medios de comunicación e información del Estado y democratizar sus espacios de comunicación.

III-3.12. Promover la soberanía comunicacional.

III-3.12.1. Divulgar el patrimonio cultural, geográfico, turístico y ambiental de Venezuela.

III-3.12.2. Construir medios de comunicación y medios de expresión de la palabra, la imagen y las voces de nuestros pueblos.

III-3.12.3. Crear un ente internacional centrado en la organización de los medios comunitarios alternativos (Minci, 2007, pp. 18-19).

Finalmente, el montaje del andamio de lo que, a decir de Bisbal (2014, p. 94), es lícito denominar el "nuevo régimen comunicativo público", sería completado por el texto titulado "Propuesta del candidato de la patria comandante Hugo Chávez para la gestión bolivariana socialista 2013-2019", oferta de gobierno presentada en vida por Hugo 
Chávez con vistas a las elecciones presidenciales llevadas a efecto el 12 de octubre de 2012, y apropiada más tarde por su sucesor, Nicolás Maduro, tras ascender a la primera magistratura el 17 de abril de 2013, si bien bajo la fórmula "Plan de la patria 2013-2019", también llamado "Segundo plan socialista 2013-2019", a la postre elevado a la categoría de ley de la nación.

A grandes rasgos, el referido documento plasma en el horizonte del próximo sexenio, en concreto en el Gran Objetivo Histórico n. 1 "Defender, expandir y consolidar el bien más preciado que hemos reconquistado después de 200 años: la Independencia Nacional", con foco sobre el Objetivo Nacional 1.1 "Garantizar la continuidad y consolidación de la Revolución Bolivariana", el deslinde de una serie de objetivos estratégicos y generales por lo que atañe al terreno comunicacional:

1.1.5. Seguir construyendo la soberanía y democratización comunicacional.

1.1.5.1. Garantizar el derecho del pueblo a estar informado veraz y oportunamente, así como al libre ejercicio de la información y comunicación.

1.1.5.2. Fortalecer el uso responsable y crítico de los medios de comunicación públicos, privados y comunitarios como instrumentos de formación de valores bolivarianos.

1.1.5.3. Consolidar la regulación y contraloría social de los medios de comunicación como herramienta para el fortalecimiento del Poder Popular.

1.1.5.4. Promover e impulsar un sistema nacional de comunicación popular.

1.1.5.5. Fomentar la investigación y formación sobre la comunicación como proceso humano y herramienta de transformación y construcción social. 
1.1.5.6. Desarrollar redes de comunicación y medios de expresión de la palabra, la imagen y las voces de nuestros pueblos, con miras al fortalecimiento de los procesos de integración y unidad latinoamericana y caribeña.

1.1.5.7. Actualizar y desarrollar de forma permanente las plataformas tecnológicas de comunicación e información, garantizando el acceso a la comunicación oportuna y ética a fin de contribuir a la satisfacción de las necesidades para el vivir bien de nuestro pueblo, entre otras.

1.1.5.8. Consolidar la adecuación tecnológica del sistema público de comunicación con el marco de la implementación de la Televisión Digital Abierta y el uso de las nuevas TIC.

1.1.5.9. Conformar un sistema de medios que contribuya a la organización sectorial para la defensa integral de la Patria, con énfasis en la consolidación de nuevos medios y formas de producir contenidos en la frontera con relevancia de los valores patrióticos y socialistas (Gaceta Oficial de la República Bolivariana de Venezuela, 2013, p. 7).

Otro tanto se puntualiza con relación a los medios de comunicación, incluso con visos inscritos en la perspectiva de la "diplomacia de los pueblos”, en el Gran Objetivo Histórico n. 4 "Contribuir al desarrollo de una nueva geopolítica internacional en la cual tome cuerpo el mundo multicéntrico y pluripolar que permita lograr el equilibrio del universo y garantizar la paz planetaria en el planeta”, concretamente por lo que entraña al Objetivo Nacional 4.1. "Continuar desempeñando un papel protagónico en la construcción de la unión latinoamericana y caribeña”:

4.1.9. Impulsar el nuevo orden comunicacional de Nuestra América, con especial énfasis en los nuevos sistemas y medios de información regionales y en el impulso de nuevas herramientas comunicacionales.

4.1.9.1. Fortalecer Telesur, garantizando una mayor presencia regional y mundial. 
4.1.9.2. Expandir el alcance de la Radio del Sur como herramienta comunicacional para la visibilización de los procesos políticos de la región.

4.1.9.3. Fomentar las redes de cadenas informativas alternativas y comunitarias en la región así como las redes sociales.

4.1.9.4. Difundir de forma permanente información veraz producida por países del ALBA y países aliados del Sur.

4.1.9.5. Garantizar la producción permanente de contenidos, para difundir a través de medios de comunicación regionales los avances económicos, sociales, políticos y culturales de la Revolución Bolivariana.

4.1.9.6. Desarrollar capacidades de producción de contenidos audiovisuales en formato digital desde y para la puesta en marcha de la Televisión Digital Abierta (TDA) a nivel nacional y para el intercambio regional (Gaceta Oficial de la República Bolivariana de Venezuela, 6118 Extraordinario, p. 23).

Estas coordenadas son rematadas en el Objetivo Nacional 4.3. "Continuar impulsando el desarrollo de un mundo multicéntrico y pluripolar sin dominación imperial y con respeto a la autodeterminación de los pueblos", lo mismo que en el Objetivo Nacional 4.4. "Desmontar el sistema neocolonial de dominación imperial”, incluyéndose en el repertorio de sus objetivos estratégicos y generales los que se resaltan de seguidas:

\subsubsection{Conformar un nuevo orden comunicacional del Sur.}

4.3.2.1. Fortalecer las cadenas multiestatales y redes comunitarias de televisión y radio, junto con sus respectivas plataformas electrónicas, expandiendo su alcance, su oferta en diferentes idiomas y la variedad y calidad de sus contenidos, con el fin de proyectar la verdad de los pueblos y romper el bloqueo informativo y la censura impuesta por las corporaciones transnacionales de la comunicación.

4.3.2.2. Establecer alianzas con las cadenas de comunicación e información de los polos emergentes del mundo para asegurar 
el conocimiento mutuo y la información veraz sobre nuestras realidades sin el filtro deformador de las grandes empresas de comunicación de las potencias imperialistas [...].

4.4.2. Reducir el relacionamiento económico y tecnológico con los centros imperiales de dominación a niveles que no comprometan la independencia nacional.

\begin{abstract}
4.4.2.3. Llevar a niveles no vitales la conexión de Venezuela con las redes de comunicación e información dominadas por las potencias neocoloniales.
\end{abstract}

\begin{abstract}
4.4.2.4. Eliminar la dependencia de sectores estratégicos para el desarrollo nacional de redes de comunicación e información controladas por las potencias neocoloniales (Gaceta Oficial de la República Bolivariana de Venezuela, 6118 Extraordinario, p. 24).
\end{abstract}

A no dudar, subyace en esta batería de disposiciones la faceta interventora del Estado, a tono con la tendencia acusada por no pocos gobiernos latinoamericanos de seño político variopinto a partir del modelaje instalado con la sanción en Venezuela de la Ley de Responsabilidad Social de Radio y Televisión (Ley Resorte) en el año 2004, en procura de ejercer un mayor control sobre los medios de comunicación en general y de los audiovisuales en particular (Llorente y Cuenca, 2013, p. 2). En este cauce, además de invocar la necesidad de regular los niveles de concentración de la propiedad con la aspiración de asegurar el acceso y la participación ciudadana en la puesta en circulación de mensajes, productos culturales y opiniones diversas, se trae al ruedo la supervisión de los contenidos y la promoción de nuevos actores sociales a las licencias audiovisuales, sin descontar el protagonismo del Estado en calidad de emisor y gestor comunicacional (Becerra, 2014, p. 72).

Con asidero en esta afirmación y a la guía de lo señalado por Gómez (2013, pp. 41-50), en el caso de Venezuela es viable emplazar, entre 2000 y 2012, dos intervalos significativos en la dinámica de la relación de los medios de comunicación social con el Estado bolivariano: un momento preliminar, susceptible de ubicarse desde 2000 a 2006, en el que básicamente 
prevalecen las modificaciones de cuño legislativo a tenor de una racionalidad política; la creación de nuevos entes reguladores como el Ministerio de Comunicación e Información (Minci), adscribiéndose a su competencia el manejo de los medios públicos, la conducción de la exposición comunicacional del Presidente de la República y la publicidad gubernamental; la reestructuración de la Comisión Nacional de Telecomunicaciones (Conatel) ${ }^{2}$ en aras de una mayor eficiencia y capacidad técnica; y la fundación tanto del Directorio de Responsabilidad Social como del Consejo de Responsabilidad Social a modo de órganos consultivos encargados de establecer el "control popular de los medios de comunicación".

De esta época data la aprobación de la Ley Orgánica de Telecomunicaciones (Lotel) en el seno de la Comisión Legislativa Nacional (CLN) ${ }^{3}$ el $1^{\circ}$ de junio de 2000, al igual que la sanción de la Ley de Responsabilidad Social en Radio y Televisión (Ley Resorte), por parte de la Asamblea Nacional, en diciembre de 2004, que fue reformada en diciembre de 2005 (Torrealba, 2013, p. 164). Como complemento a la legislación sobre comunicación, acompañaron a las normativas antes referidas la Ley Orgánica para la Protección de Niños, Niñas y Adolescentes (2000) y el Reglamento de Radiodifusión Sonora y Televisión Abierta Comunitarias de Servicio Público sin fines de lucro (2002) (Hernández y Reina, 2010, p. 26).

Con el advenimiento del año 2006 se inició un segundo periodo orientado a la ampliación de los medios estatales y el robustecimiento de la red de medios comunitarios, aparte del despliegue de procedimientos administrativos susceptibles de desembocar en multas oscilantes entre el 3 y el $4 \%$ de los ingresos brutos obtenidos por la empresa de medios durante el ejercicio fiscal anterior a la fecha en la cual empezó su proceso.

En esta vertiente, el hecho más emblemático fue la no renovación de la concesión al canal de televisión de señal abierta Radio Caracas Televi-

2 La Comisión Nacional de Telecomunicaciones (Conatel) fue fundada en 1991 a través del Decreto 1.826 en tanto primer organismo destinado a controlar el sistema de medios de comunicación en Venezuela con carácter de servicio autónomo y sin personalidad jurídica. Reemplazó en funciones al Consejo Nacional de Telecomunicaciones.

3 La Comisión Legislativa Nacional, también conocida como "Congresillo", fue el órgano que cumplió tareas parlamentarias durante la transición entre la aprobación de la Constitución de la República Bolivariana de Venezuela en 1999 y la instalación del nuevo órgano legislativo (Asamblea Nacional). 
sión (RCTV), tal como lo anunció el para entonces Presidente de la República, Hugo Chávez, el 28 de diciembre de 2006, alegando la violación del artículo 29 de la Ley de Responsabilidad Social en Radio y Televisión (Ley Resorte), en el que se señala que a los medios que promuevan, hagan apología o inciten a la guerra o alteraciones del orden público, se les puede suspender o revocar su concesión. Dadas las circunstancias, a las 12:01 minutos de la noche del 28 de mayo de 2007 comenzaron las transmisiones del nuevo canal TVES con salida a través de la señal de RCTV, viéndose obligada esta a migrar hacia la televisión por suscripción bajo la denominación de Radio Caracas Internacional (RCTV Internacional). A mediados de enero de 2010 se produjo su desenlace al ser alcanzadas las empresas de televisión por suscripción por la Ley de Responsabilidad Social de Radio y Televisión (Ley Resorte), lo que llevó a RCTV Internacional a ser catalogada como Productor Nacional Audiovisual, haciendo su situación financiera insostenible ante la limitación de los ingresos por concepto de publicidad (Guzmán y Quintero, 2009, pp. 183-184).

Al ritmo de esta andadura, el 20 de diciembre de 2010 fue reformada la Ley Orgánica de Telecomunicaciones con aprobación de la Asamblea Nacional, y fue publicada en la Gaceta Oficial Extraordinaria 6015 del 28 de diciembre de ese año. El nuevo texto otorgó al Ejecutivo, aduciendo motivos de seguridad nacional, la potestad de revertir licencias para operar estaciones de radio y televisión, al tiempo que redujo la duración de las habilitaciones administrativas y de las concesiones para operar estaciones de radio y televisión de 25 a 15 años. Igualmente, estableció que la Comisión Nacional de Telecomunicaciones (Conatel), anteriormente adscrita al Ministerio del Poder Popular para las Obras Públicas y Vivienda, pasara a la jurisdicción de la Vicepresidencia Ejecutiva de la República, invistiéndolo de un sesgo político y restándole competencia técnica (Torrealba, 2013, p. 169).

Otros aspectos relevantes contemplados por la normativa refieren a la facultad conferida a Conatel para cambiar, por razones de seguridad, la asignación de frecuencias y bandas que hayan sido otorgadas en concesión. Además, estipula la libre remoción del director general de Conatel y de los miembros del consejo directivo y sus suplentes por parte del presidente de la República (Gómez, 2013, p. 43). De contado, le adjudica un carácter 
"personalísimo" al derecho de uso y explotación de una concesión del espectro radioeléctrico, por lo que la misma no podrá cederse ni enajenarse. Asimismo, deja abierta la posibilidad del asentamiento de un monopolio estatal en radio y televisión (Torrealba, 2013, p. 170).

Paralelamente, el 20 de diciembre de 2010 también fue aprobada por la Asamblea Nacional la reforma definitiva a la Ley de Responsabilidad Social en Radio y Televisión, que incluye en lo sucesivo regulaciones a los medios electrónicos, por lo que su nombre cambió a Ley de Responsabilidad Social en Radio, Televisión y Medios Electrónicos. Su artículo 27 prohíbe a los servicios de radio, televisión y medios electrónicos la difusión de mensajes que inciten o promuevan el odio y la intolerancia por razones religiosas, políticas, por diferencia de género, por racismo o xenofobia; inciten o promuevan y/o hagan apología al delito; constituyan propaganda de guerra; fomenten zozobra en la ciudadanía o alteren el orden público; desconozcan a las autoridades legítimamente constituidas; induzcan al homicidio; e inciten o promuevan el incumplimiento del ordenamiento jurídico vigente. En esta línea los proveedores de medios electrónicos están obligados a activar mecanismos que permitan "restringir" la difusión de estos mensajes a solicitud de la Comisión Nacional de Telecomunicaciones (Conatel), quedando a discreción del organismo el hacer cumplir esta norma (Torrealba, 2013, p. 171).

En cuanto a las sanciones, la legislación contempla en el numeral 1 del artículo 29, la suspensión hasta por 72 horas continuas de las transmisiones o multas de hasta un $10 \%$ de los ingresos brutos causados en el ejercicio fiscal inmediatamente anterior a aquel en el cual se cometió la infracción. En simultáneo, en el numeral 2 se establece la revocatoria de la habilitación y la concesión para quienes promuevan o hagan apología, inciten o difundan propaganda de guerra, sean contrarios a la seguridad de la nación o insten al homicidio. En la reforma de la Ley también se modificó el artículo 20, sobre la conformación del Directorio de Responsabilidad Social, incrementando a 12 sus integrantes, de los cuales ocho son representantes de organismos gubernamentales, lo que entraña un desbalance que puede derivar en un sesgo al momento de tomar decisiones y prescribir sanciones (Torrealba, 2013, pp. 171-172). 
En el tramo temporal más cercano a 2013, funcionarios vinculados al Gobierno nacional formularon propuestas para crear o reformar leyes con un espíritu proclive a la censura previa y la vulneración de la libertad de expresión. Una de ellas fue el llamado Proyecto de Ley Especial Contra los Delitos Mediáticos, el cual fue rechazado al igual que la petición, en la reforma de la Ley de Telecomunicaciones aprobada en diciembre de 2010, de establecer un punto único de interconexión o acceso a la red de proveedores de Internet para manejar el tráfico entrante o saliente de Venezuela.

Con ajuste a estas evidencias, pues, se constata cómo ha venido ganando consistencia la figura del "estado legalista" que, valiéndose del recurso de medidas "menos evidentes, más sutiles y sofisticadas" sentencia judicial, sanciones penales y procedimientos administrativos, aplicadas selectivamente en perjuicio del sistema comunicacional privado e inclusive del comunitario, apuesta por el incremento de los niveles de control político y la censura (directa e indirecta), interfiriendo con la independencia de los medios, a la par que coartando el libre fluir de las ideas y las opiniones.

\section{Cuadro de los medios de comunicación privados}

A ciencia cierta, desde los albores de la radio y la televisión en Venezuela hasta principiar la "era Chávez", la fotografía de los medios de comunicación social en el país exhibía, ante propios y extraños, un sistema mixto dominado por el sector privado-comercial en razón del número de unidades comunicacionales sujetas a su gestión, al lado del cual coexistía un menguado sector de medios públicos u oficiales, quedando a duras penas el tercer sector de medios, de cariz alternativo-comunitario, como una referencia teórica.

En función de esta constante, la concentración de la propiedad en pocas manos determinó, en grado sumo, la estructura de medios de comunicación en Venezuela, distinguiéndose en particular dos grupos económicos por acumular la mayor cantidad de emisoras de radio y canales de televisión, léase Grupo 1 Broadcasting Caracas (Grupo 1-BC), ligado a la familia Phelps, y la Organización Diego Cisneros, perteneciente a la familia Cisneros (Gómez, 2013, p. 56). 
Con el tiempo, ambos conglomerados evolucionarían y dejaron atrás el estadio de cadenas mediales stricto sensu extendidas inclusive hacia ámbitos económicos en los que las industrias culturales, abocadas al entretenimiento, la información/opinión y la publicidad no eran su única actividad, para transformarse en modernas corporaciones multimedia menos vinculadas a intereses familiares y más proclives siguiendo la batuta de la globalización y la internacionalización, a la diversificación dentro del coto infocomunicacional -telecomunicaciones, informática, industria gráfica, merced al forjamiento de alianzas y fusiones con grupos transnacionales (Mastrini y Becerra, 2007, p. 21).

No obstante, suscribiendo a Pellegrino (2010), el surgimiento en Venezuela de grupos que conjuntaran en racimos industrias mediáticas y otros renglones productivo-comerciales no comportó solamente la persecución de sinergias organizacionales y plusvalías financieras, además de la disminución del riesgo de negocio por "efecto cartera", sino también la disolución de "responsabilidades fiscales, laborales y civiles, ocultando detrás de un imbricado bosque de personas jurídicas al definitivo propietario", fuese este un grupo familiar o económico (pp. 46-47).

Ateniéndose a esta realidad, transcurridos quince años de administración gubernativa bolivariana tomando en consideración los tres periodos presidenciales consecutivos de Hugo Chávez y el primer año cumplido por Nicolás Maduro en la Primera Magistratura, es fácil entrever que la mixtura del modelo de propiedad de antaño efectivamente aún se mantiene, si bien con una inversión de las cargas que, además de someter a los medios de propiedad privada a los rigores de la profesionalización y la especialización del mercado cultural-simbólico, transversalizada por la convergencia tecnológica, les ha resituado en el tablero de un nuevo orden comunicacional bajo el peso de lo que la profesora venezolana Silvia Cabrera ha dado en llamar un modelo "mixto-autoritario", conforme al cual el Estado ejerce un control político y fuertes presiones de índole administrativa que cercan el pluralismo y la diversidad en términos informativos y de opinión (Cañizález, 2013, p. 178). 


\section{Cuadro 2 \\ Grupos de comunicación en Venezuela}

\begin{tabular}{|c|c|}
\hline $\begin{array}{l}\text { 1Broadcasting Caracas } \\
\qquad(1-\mathrm{BC})\end{array}$ & $\begin{array}{l}\text { Posee una estructura de integración y concentración de propiedad similar a la de su competidora } \\
\text { Organización Cisneros (ODC). Hasta el año } 2007 \text { en su portafolio figuraba el canal de señal } \\
\text { abierta Radio Caracas Televisión (RCTV), migrado por breve lapso a la televisión por suscripción } \\
\text { bajo la denominación RCTV Internacional. A la fecha dispone de las emisoras Radio Caracas } \\
\text { Radio (RCR) } 750 \text { AM y } 92.9 \text { FM. También es dueño de la disquera Recorland, amén de una } \\
\text { empresa comercializadora de sus producciones a nivel internacional, la Coral Pictures, con sede } \\
\text { en la ciudad de Miami. }\end{array}$ \\
\hline $\begin{array}{l}\text { Organización Diego } \\
\text { Cisneros (ODC) }\end{array}$ & $\begin{array}{l}\text { Forma parte de un holding industrial con múltiples inversiones en diferentes áreas de la economía. } \\
\text { En Venezuela su negocio abarca el canal de señal abierta Venevisión, el Circuito Radial FM } \\
\text { Center, la compañía discográfica Rodven y la televisora por suscripción DirecTV. Fuera de los } \\
\text { límites del país, ha alcanzado una importante expansión en el control de estaciones de televisión } \\
\text { en América Latina, con participación accionaria en Chile (Chilevisión), Colombia (Caracol) } \\
\text { y el Caribe (Caribean Communication Network). Por añadidura, es la mayor accionista de la } \\
\text { cadena norteamericana Univisión y de la señal de Galavisión, las dos orientadas al público de } \\
\text { habla hispana en los Estados Unidos. }\end{array}$ \\
\hline Bloque de Armas & $\begin{array}{l}\text { Comprende la televisora Meridiano Televisión, la emisora Meridiano Radio Deportes y el diario } \\
\text { Meridiano Deportes, así como el rotativo } 2001 \text { de información general. En el ámbito de las revistas, } \\
\text { integran su cartera, entre otras, Variedades, Ronda y Playboy Venezuela. }\end{array}$ \\
\hline Grupo Camero & Es propietario de la Televisión Venezolana C.A. (Televen). \\
\hline Grupo Capriles & $\begin{array}{l}\text { Otrora socio del Bloque de Armas en la explotación, para Venezuela, de los productos de la empresa } \\
\text { editorial norteamericana Continental Publishing Co., hoy en día es su competidor directo. Hasta } \\
\text { el } 13 \text { de mayo de } 2013 \text { editaba tres periódicos: Ultimas Noticias (información general), El Mundo } \\
\text { Economia y Negocios (información económica) y "Líder" (información deportiva). Fue vendido } \\
\text { a una banca de inversiones inglesa denominada Hanson Asset Management, que la adquirió por } \\
\text { medio de su filial Latam Media Holding. }\end{array}$ \\
\hline Grupo Otero & Es dueño del periódico El Nacional. Ha ampliado su negocio editorial hacia la rama de los libros. \\
\hline Grupo Mata & $\begin{array}{l}\text { Hasta el pasado } 4 \text { de julio de } 2014 \text { era propietario del diario El Universal, ahora perteneciente a } \\
\text { la firma española de inversiones Epalisticia. }\end{array}$ \\
\hline
\end{tabular}

Fuente: elaboración propia a partir de Pellegrino (2010, pp. 47-48).

Al margen de los intríngulis relativos a la propiedad, el paisaje mediático venezolano tampoco estuvo exento de cambios en el trajín de la pasada década, y superó la imagen grabada por Guzmán (2001, pp. 218-222) que mostraba, para el año 1998, un ecosistema integrado por 124 diarios y 375 emisoras de radio AM y FM, 14 canales en señal VHF (cuatro de televisión de cobertura nacional, tres regionales y siete estadales); 20 canales UHF (tres regionales y 17 estadales), y 16 servicios de televisión por suscripción.

De tal suerte, siguiendo los datos suministrados por Quiñones, Bisbal y Aguirre (2012, pp. 61 y ss.), la composición de la cesta de medios de 


\section{comunicación social en Venezuela, en la actualidad, puede dibujarse, gros- so modo, como se muestra a continuación.}

\section{Cuadro 3 \\ Composición de los Medios de Comunicación en Venezuela}

\begin{tabular}{|c|c|}
\hline Prensa & $\begin{array}{l}\text { Por lo que respecta a las publicaciones periódicas, en el catálogo se cuentan } 87 \text { rotativos distribuidos } \\
\text { entre las distintas regiones del país: región oriental ( } 21 \text { periódicos), región capital ( } 14 \text { diarios), región } \\
\text { de los llanos ( } 13 \text { rotativos), región centro occidente ( } 11 \text { periódicos), región zuliana (cinco diarios), } \\
\text { región andina (ocho rotativos), región sur (siete periódicos) y región central (ocho diarios). Según } \\
\text { cálculos, los ocho principales rotativos regionales (Panorama, Crítica, El Carabobeño, La Columna, La } \\
\text { Nación, El Impulso, El Informador y El Tiempo), tienen un tiraje aproximado de } 200.000 \text { ejemplares } \\
\text { por día, mientras que los periódicos de la zona metropolitana de Caracas (El Nacional, El Universal y } \\
\text { Últimas Noticias) hacen lo propio con un tiraje de } 350.000 \text { ejemplares diarios. En general, todos han } \\
\text { evolucionado en materia de diseño, apostando además por la presencia en Internet ylas redes sociales, } \\
\text { lo que ha traído consigo una modificación en la forma tradicional de procesar y presentar los contenidos } \\
\text { al lector. Dado el ambiente de conflictividad política y social escenificado en Venezuela en el transcurso } \\
\text { de los primeros meses de 2014, diez periódicos cesaron forzosamente sus operaciones, mientras que } \\
33 \text { permanecieron activos aunque con menos paginación ante la ausencia de divisas para la compra de } \\
\text { materias primas como el papel e insumos para la impresión. }\end{array}$ \\
\hline Radio & $\begin{array}{l}\text { A grandes pinceladas, en el país existen unas } 600 \text { estaciones, en su mayoría privadas-comerciales, de las } \\
\text { cuales dos terceras partes transmiten en frecuencia modulada (FM). Ello ha significado variaciones en el } \\
\text { estilo de programación, con una clara tendencia hacia la segmentación de contenidos, atendiendo a las } \\
\text { preferencias de las audiencias (musicales, informativas y de opinión). De a poco han ido incorporándose } \\
\text { a las redes sociales, lo que les imprime un rasgo interactivo y actual. En los últimos años el medio ha } \\
\text { venido experimentando un proceso de desconcentración fuera de la zona metropolitana y central de } \\
\text { Venezuela, que se traduce en un incremento del número de emisoras regionales. Por lo que se refiere al } \\
\text { régimen de propiedad, operan al abrigo de dos modalidades: la propiedad bajo la misma personalidad } \\
\text { jurídica yla integración en cadenas. A la fecha, los circuitos más importantes en virtud de su facturación } \\
\text { publicitaria, audiencia y calidad de programación son Unión Radio/Mega/Onda y Exitos, imbricada } \\
\text { con Unión Radio Noticias para un total de } 48 \text { estaciones (ocho en AM y } 40 \text { en FM); FM Center/ } \\
\text { Fiesta/La Romántica, con } 39 \text { emisoras en FM y } 15 \text { en AM; Rumbera, con } 23 \text { estaciones en FM; Triple } \\
\text { F, con } 22 \text { emisoras en FM; Circuito X, con } 15 \text { estaciones en FM, y Planeta con } 13 \text { emisoras en FM. } \\
\text { De este listado deben retirarse aproximadamente unas } 35 \text { estaciones que, con el Circuito Nacional } \\
\text { Belfort (CNB), fueron objeto de una sanción por parte del Gobierno nacional entre } 2008 \text { y 2009 tras } \\
\text { abrírseles un expediente administrativo. Otros } 32 \text { circuitos más pequeños aglutinan, en su conjunto, a } \\
110 \text { emisoras comerciales. En paralelo, dos circuitos radiofónicos cobijan a un número nada despreciable } \\
\text { de estaciones no comerciales, en detalle: Radio Noticias Fe y Alegría (12 emisoras entre FMy AM) yla } \\
\text { Corporación Venezolana de Radiodifusión (CRV), que reúne a más de } 85 \text { estaciones (Radio Nacional } \\
\text { de Venezuela en AM y FM, YVKE Mundial en AM y FM y Radio del Sur). Suma a este cauce la salida } \\
\text { al aire de numerosas emisoras comunitarias cuyas frecuencias de transmisión, en algunos casos, limitan } \\
\text { o interfieren con las de las estaciones comerciales. }\end{array}$ \\
\hline
\end{tabular}




\begin{tabular}{|c|c|}
\hline & $\begin{array}{l}\text { En lo atinente a la televisión de señal abierta, en el espectro figuran cuatro canales de cobertura nacional: } \\
\text { Venevisión, Televen, TVES y Venezolana de Televisión, estos últimos propiedad del Estado. Igualmente, } \\
\text { entre sus haberes destacan dos canales de cobertura nacional limitada: Globovisión y Meridiano } \\
\text { TV, al tiempo que continúan sus operaciones las televisoras especializadas Canal I y Vale TV. Por su } \\
\text { parte, en la franja regional existen } 40 \text { televisoras que compiten entre sí y con los canales nacionales, } \\
\text { agrupadas en circuitos desde el año 2006, a semejanza de la práctica implementada por las estaciones } \\
\text { radiofónicas, para compartir información y programación, así como para distribuir y regionalizar las } \\
\text { pautas publicitarias. Dentro de estas alianzas merecen mencionarse el grupo Televisión Regional (TVR), } \\
\text { que articula a Global TV, TAM, TRT, TVO y TVS; el Grupo Nacional de Televisión, compuesto por } \\
\text { Canal 21, NTV Televisión; OMC Televisión; Mira TV, Telellano, Total TV, Trujillo TV y Universal } \\
\text { Televisión, y el Circuito Venezolano de Televisión Nacional (CVTN), formado por Contac TV, Jerga } \\
\text { Visión, Nautavisión, DAT TV, TV Familia, TV Proclamación, Somos TB, V + TV, Sol Televisión, } \\
\text { Olímpica Televisión, Telesol, Atel TVy Telecolor. Valga acotar que la audiencia en televisión abierta } \\
\text { ha ido descendiendo debido, fundamentalmente, a la competencia planteada por la televisión por } \\
\text { suscripción y a la salida del aire de RCTV. Fijando la mira sobre el tema de las concesiones, justo es } \\
\text { señalar que, entre 1999y } 2009 \text {, se otorgaron } 69 \text { concesiones de televisión abierta para medios privados } \\
\text { comerciales (48,10\%); } 37 \text { concesiones para televisoras comunitarias (46,84\%) y seis concesiones para } \\
\text { canales gubernamentales (5,06\%). }\end{array}$ \\
\hline $\begin{array}{l}\text { Televisión por } \\
\text { suscripción }\end{array}$ & $\begin{array}{l}\text { El Observatorio Estadístico de Conatel da cuenta de } 165 \text { empresas que ofrecen este servicio, conforme } \\
\text { a cifras de 2011, siendo las principales operadoras DirecTV, Intercable, SuperCable, NetUno y Movistar. } \\
\text { Su crecimiento ininterrumpido (a una tasa interanual un poco mayor del } 11 \% \text { y una penetración del } \\
\text { 39,4\%) representa una amenaza para la televisión de señal abierta, mermada después de la no renovación } \\
\text { de la concesión a RCTV, circunstancia que devino en el aumento del número de suscriptores de cable. } \\
\text { Luego de la renacionalización de la CANTV, el sector público comenzó a prestar un servicio de televisión } \\
\text { satelital de bajo coste que, hasta ahora, alcanza los } 120.000 \text { suscriptores. }\end{array}$ \\
\hline $\begin{array}{c}\text { Televisión digital } \\
\text { abierta (TDA) }\end{array}$ & $\begin{array}{l}\text { El } 21 \text { de julio de } 2009 \text { Venezuela inició su incursión en la televisión digital después del anuncio realizado } \\
\text { por el gobierno bolivariano en la senda de adoptar el sistema japonés conocido como Integrated Services } \\
\text { Digital Broadcasting Terrestrial (ISDB-T) con la asistencia de la tecnología brasileña (ISDB-Tb49). } \\
\text { Las pruebas comenzaron con un año de retraso en Caracas y se hicieron para difundir tres tipos de } \\
\text { señales: estándar, alta definición y para dispositivos móviles. Los primeros canales en implementar la } \\
\text { tecnología digital, a partir del } 6 \text { de octubre de 2009, fueron los estatales VTV y Colombeia. Con ello } \\
\text { se dio inicio a la cuenta regresiva para el cambio o "apagón analógico". En } 2012 \text { Argentina firmó un } \\
\text { acuerdo con Venezuela para la instalación de trece estaciones de transmisión de televisión digital, y a } \\
\text { continuación se creó la Comisión Nacional Presidencial para la Televisión Digital Terrestre, integrada } \\
\text { por un grupo multidisciplinario de profesionales a quienes se les encomendó la gestión de la TDA en el } \\
\text { país. Desde febrero de } 2013 \text { un total de } 11 \text { canales transmiten bajo este sistema digital, en concreto: VTV, } \\
\text { Telesur, TVES, Televen, Venevision, Meridiano TV, ANTV, Vive TV, } 123 \text { TV, La Tele y Colombeia, } \\
\text { en coexistencia con la tecnología analógica hasta } 2021 \text {. Pese a esta realidad, aún no existe un marco } \\
\text { normativo que rija su funcionamiento. }\end{array}$ \\
\hline
\end{tabular}

Fuente: elaboración propia a partir de Quiñones, Bisbal y Aguirre (2012, pp. 61 y ss.). 
Por lo demás, una cartografía de los medios de comunicación social en Venezuela no estaría del todo completa si no se aludiera, por lo menos brevemente, a algunos hechos acaecidos recién, centrados en la adquisición intempestiva de tres empresas del sector de propiedad privada. En este sentido, ciñéndose a una secuencia cronológica, menester es nombrar, en primer lugar, al canal de noticias Globovisión, propiedad de la familia Zuloaga y durante muchos años la única pantalla abierta a la bancada de oposición al Gobierno nacional, vendido en abril de 2013 a un grupo de inversionistas ligados al sector asegurador y bancario —específicamente a la compañía La Vitalicia, entre quienes figuran Juan Domingo Cordero, Gustavo Perdomo y Raúl Gorrín-. Hoy en día, bajo el eslogan "Noticias estés donde estés", Globovision pone en evidencia un viraje en su línea editorial e informativa, y se define como un canal que "debe darle cabida a las denuncias y críticas de esta sociedad e, inclusive, a sus funcionarios públicos y líderes en general, pero preservando el respeto y la objetividad. Le brindamos una pantalla más amigable y dinámica que no pierde de vista nuestra razón de ser: la noticia” (Bisbal, 2014, p. 95).

El segundo caso por puntualizar corresponde al de la Cadena Capriles, grupo fundado por Miguel Ángel Capriles, con una trayectoria a cuestas de 70 años, adquirido el 31 de mayo de 2013 por una banca de inversiones inglesa denominada Hanson Asset Management, la cual se sirvió de los oficios de intermediación de su filial Latam Media Holding, aun cuando no faltaron las versiones que apuntaban hacia el banquero Víctor Vargas, dueño del Banco Occidental de Descuento (BOD), como el posible nuevo propietario, lo que fue desmentido.

A la fecha, periodistas destacados han hecho manifiesto su desacuerdo con la nueva línea informativa, llegando a renunciar a sus puestos de trabajo en el diario Últimas Noticias. Entretanto, el comunicador social Omar Lugo, director del rotativo El Mundo. Economía y Negocios, perteneciente a la cartera de productos de la empresa, fue despedido expresamente por solicitud de los compradores. A contramano, la exdiputada Desiré Santos Amaral, militante del Partido Socialista Unido de Venezuela (PSUV), fue llamada para actuar como Consejera Editorial (Bisbal, 2014, p. 96). 
Trae más agua a este molino la venta del periódico El Universal, con 105 años de existencia, propiedad de la familia Mata desde su fundación por el poeta Andrés Mata. El día 3 de julio de 2014 fue confirmado su traspaso accionario a favor de la firma española de inversiones Epalisticia — dedicada a las áreas de petróleo, bienes raíces y medios de comunicación-, en la persona del ingeniero Jesús Alfonso Rafael Abreu, a la postre nuevo presidente del diario, quien afirmó que el grupo comprador no "tiene ninguna vinculación con el Gobierno nacional”, dio su palabra de que la línea editorial no variaría y aseguró que todo el personal seguiría laborando como lo venía haciendo. Asimismo, indicó que Epalisticia trae consigo un plan de generación de valor a largo plazo y la introducción de innovaciones tecnológicas que acelerarán el proceso de digitalización del rotativo (El Universal, 5 de julio, 2014).

Para finalizar este segmento, se trae a colación la información extraoficial, ventilada por el periodista Diego Kapeky del diario La Voz, en torno a la compra de la televisora Venevisión — propiedad de la Organización Diego Cisneros-, por el Gobierno bolivariano, con la expectativa de salir al aire como señal estatal a partir del $1^{\circ}$ de enero de 2015.

En suma, por lo que atañe a las cuestiones de propiedad y composición, el mapa mediático venezolano entretejido de 1999 en adelante luce distinto en su fisonomía e incidencia al de los lustros anteriores, con un sector privado todavía en pie, pero fagocitado por el Estado/Gobierno que, en gran medida, ha desplazado la inversión publicitaria utilizándola como una herramienta de sanción (Pellegrino, 2010, pp. 50-51), cuando no como un instrumento de distribución de subsidios para estimular el desarrollo de nuevos emprendimientos de comunicación directa que permitan prescindir del rol mediador que los privados llevaron a cabo en el transcurso de décadas sin competencia alguna (Becerra, 2014, pp. 65, 68).

\section{Cuadro de los medios de comunicación públicos}

De acuerdo con lo apuntado por la consultora Llorente y Cuenca en su informe especial "Panorama audiovisual en América Latina. Concentración y renovación tecnológica” (2013), en el enmarcado de un curso de acción verificado en América Latina a lo largo de la última década, en el que Argentina, 
Bolivia, Ecuador y Venezuela son dignos representantes de la corriente en cuestión, el Estado se ha transformado en un agente de comunicación que, a través de los órganos públicos de difusión, se enfila a competir y disputar audiencias a los grupos privados en igualdad de condiciones (p. 12).

Extrapolando esta aseveración al contexto venezolano hasta ahondar en los pormenores de los hallazgos arrojados por el proyecto de investigación "Situación mediática y crisis política", coordinado por la profesora Mariela Torrealba, de la Escuela de Comunicación Social de la Universidad Central de Venezuela (UCV), ciertamente es dable admitir el crecimiento sostenido experimentado por el parque mediático estatal desde el año 2002 al abrigo del denominado "Sistema Nacional de Medios Públicos", formalizado a propósito de la segunda gestión de Andrés Izarra al frente del Ministerio del Poder Popular para la Comunicación e Información (Minci) entre 2008 y 2009, y sustituido recién en el mes de febrero de 2013 por el "Sistema Bolivariano de Comunicación e Información” ( $\mathrm{SiBCI}$ ), por cuyo intermedio se centralizan todas las actividades de los medios de comunicación tanto públicos como comunitarios, poniendo el acento sobre la comunicación popular gestionada a través de "comunicadores de calle".

Huelga atisbar aquí, de resultas, una vuelta de tuerca en comparación con la situación reinante en 1999 cuando, al arribo a las funciones de gobierno, Hugo Chávez y su tren ejecutivo hallaron una plataforma de medios estatales precaria por lo que incumbe al instrumental tecnológico y el presupuesto, tanto así que, en el estudio "Gobernabilidad democrática en Venezuela. Hacia un sistema de difusión de servicio público” (1998, citado por Torrealba, 2009, p. 156), rubricado por la Comisión para la Reforma del Estado (Copre), con el apoyo del Programa de Naciones Unidas para el Desarrollo (PNUD) y la Organización de las Naciones Unidas para la Educación, la Ciencia y la Cultura (Unesco), el diagnóstico fue reseñado bajo los siguientes términos

En general la aportación del Estado venezolano en sus propios medios de difusión es baja: no llega al 0,05\%, incluyendo los presupuestos asignados por el Estado a VTV y a Radio Nacional [...]. Además se señala en la propuesta que los medios estatales (en particular la TV) 
han perdido terreno en audiencia, calidad e infraestructura técnica de transmisión y producción.

Obedeciendo a esta tónica, al cierre de 1998 la administración gubernativa saliente de Rafael Caldera apenas contaba con un canal de televisión en frecuencia VHF, léase Venezolana de Televisión (VTV); la Radio Nacional de Venezuela (RNV), dotada de cuatro señales, dos en amplitud modulada - Antena Informativa y Antena Popular-, una en frecuencia modulada — Canal—, y una en onda corta, y la agencia de noticias Venpres, la cual llegó a contar con corresponsales en diversos países del mundo durante el segundo mandato de Carlos Andrés Pérez (1989-1993). Entretanto, el Estado venezolano conservaba en sus manos ocho emisoras de radio de las 41 que fueron entregadas al Fondo de Garantía de Depósitos y Protección Bancaria (Fogade) por los préstamos otorgados al Banco Latino al calor de la crisis bancaria de 1994 .

A la vista de esta estampa de rezago tecnológico, alcance limitado e ínfimo impacto, el Gobierno bolivariano emprendió el fortalecimiento de la red de medios del Estado potenciando los espacios ya existentes con sofisticado equipamiento - para llegar a todo el territorio nacional y allende las fronteras - , renovada infraestructura y remozado personal, sumados a la inyección de recursos financieros acompasada a la adquisición y la creación de nuevos medios, especialmente en el sector radioeléctrico, pero sin descuidar los ámbitos impreso y digital (Quiñones, Bisbal y Aguirre, 2012, p. 21).

A la sazón, un inventario siquiera escueto de la pluralidad de medios gubernamentales existentes en Venezuela que no públicos, en la opinión de Bisbal (2013, p. 60), toda vez que se "concentran en un triángulo programático fundamentado en la propaganda, la información y opinión política”, decanta en el cuadro que se expone a continuación.

A todas estas, en el reducto de las telecomunicaciones, mención aparte amerita el establecimiento de la empresa Corporación Venezolana de Guayana (CVG-Telecom) en septiembre de 2004, con el ánimo de poner en valor una red de alta velocidad destinada al transporte de datos, lo mismo que a la provisión de servicios de Internet y televisión por cable a lo- 


\section{Cuadro 4 \\ Sistema bolivariano de comunicación e información (SiBCI)}

\begin{tabular}{|c|c|}
\hline \multirow{4}{*}{ Prensa } & $\begin{array}{l}\text { - El Correo de Orinoco: diario de circulación nacional, de formato tabloide. Cuenta con una edición en } \\
\text { inglés. Ofrece contenidos periodísticos y de opinión. Una vez a la semana incluye con carácter gratuito } \\
\text { Semanario Cultural del Poder Popular Todos Adentro. Adicionalmente, cada domingo intercala el encartado } \\
\text { de revistas de distribución gratuita que forman parte del Sistema Masivo de Revistas del Ministerio de } \\
\text { Poder Popular para la Cultura, en concreto: A Plena Voz, Arte de Leer, Así Somos, La Revuelta, La Roca de } \\
\text { Crear, Memorias de Venezuela, Poder Vivir y Se Mueve. }\end{array}$ \\
\hline & $\begin{array}{l}\text { - Ciudad CCS: diario de formato tabloide editado por la Alcaldía Metropolitana de Caracas. Su distribución } \\
\text { es gratuita. Brinda contenidos periodísticos y de opinión. }\end{array}$ \\
\hline & $\begin{array}{l}\text { - Palabra y Media: publicación quincenal del Ministerio del Poder Popular para la Comunicación y la a } \\
\text { Información (Minci). Solo circuló durante el 2005, año de su aparición. En sus páginas se reseñaban las } \\
\text { políticas comunicacionales del Gobierno. }\end{array}$ \\
\hline & $\begin{array}{l}\text { - Fundación Imprenta de la Cultura (“La Imprenta de la Revolución”): centrada en la producción de } \\
\text { "libros para la gente" como propuesta comunicacional. De sus talleres han salido textos que responden a } \\
\text { diversos formatos y contenidos: historia, ensayo, narrativa, poesía, infantil, pedagogía, ciencia, tecnología } \\
\text { popular, comunicaciones, discursos presidenciales, afiches. }\end{array}$ \\
\hline \multirow{6}{*}{ Televisión } & $\begin{array}{l}\text { A la vuelta de una década, el gobierno bolivariano dispone de una plataforma de } 13 \text { canales de televisión, } \\
\text { siendo los de factura más antigua: }\end{array}$ \\
\hline & $\begin{array}{l}\text { - Venezolana de Televisión (VTV): salió al aire en el año } 1974 \text {. Ha ido cambiando y modernizando su } \\
\text { tecnología hasta ampliar la cobertura del Canal } 8 \text { a todo lo largo y ancho de Venezuela. Se considera } \\
\text { principal canal del Estado. En el } 2005 \text { se le instalaron } 47 \text { nuevos transmisores como parte del plan de } \\
\text { reforzamiento de la distribución de la señal, además de habilitarle tres nuevos estudios y una sala de prensa } \\
\text { con equipos de alta tecnología digital. }\end{array}$ \\
\hline & $\begin{array}{l}\text { Vive TV: nacido el } 11 \text { de noviembre de } 2003 \text {. Cuenta con una red de productores independientes y una } \\
\text { Escuela Latinoamericana de Documentales. Depende totalmente del presupuesto nacional asignado } \\
\text { al Minci. Se define como "[...] un medio de comunicación del Estado venezolano, educativo, cultural } \\
\text { e informativo que impulsa la democracia participativa y protagónica, la solidaridad y la integración } \\
\text { latinoamericana desde un nuevo paradigma de comunicación en sintonía con el nuevo modelo político } \\
\text { económico y social establecido en la Constitución de la República Bolivariana de Venezuela" (www } \\
\text { vive.gob.ve/vive.php). }\end{array}$ \\
\hline & $\begin{array}{l}\text { - Telesur: fue puesto en marcha en } 2005 \text { bajo la concepción de un canal de alcance regional "que permita } \\
\text { a todos los habitantes de esta región, difundir sus propios valores, divulgar su propia imagen, debati } \\
\text { sus propias ideas y transmitir sus propios contenidos, libre y equitativamente" (www.telesur.net). Puede } \\
\text { sintonizarse por cable o satélite. Recibe el respaldo financiero y logístico mayoritario del gobierno de } \\
\text { Venezuela y, en menor medida, de Cuba, Bolivia, Ecuador, Nicaragua, Uruguay y Argentina, en e } \\
\text { entendido de que el canal forma parte de una sociedad multiestatal. Su presupuesto anual asciende a } \\
50 \text { millones de dólares. Cuenta con una plantilla de } 400 \text { empleados y } 12 \text { oficinas en el extranjero. Surge } \\
\text { como una alternativa a los proyectos comunicacionales de imagen y pensamiento único. }\end{array}$ \\
\hline & $\begin{array}{l}\text { - Televisora Metropolitana Avila TV: inició sus transmisiones en octubre de 2006, declarándose una } \\
\text { "televisora [...] cuya programación está orientada principalmente hacia la exaltación de los valores } \\
\text { culturales de la ciudad". En sus orígenes dependía directamente de la Alcaldía Mayor, pero, después de } \\
\text { triunfo en } 2008 \text { del candidato de la oposición en esa instancia, Antonio Ledezma, el canal fue incorporado } \\
\text { al Sistema Nacional de Medios Públicos con una programación juvenil. Se puede sintonizar por el Canal } \\
47 \text { por frecuencia UHF y por Intercable a través del Canal } 94 \text {. }\end{array}$ \\
\hline & $\begin{array}{l}\text { Asamblea Nacional TV (ANTV): empezó sus actividades el } 17 \text { de febrero de 2006, adscrito al Poder } \\
\text { Legislativo. Se pone en el aire por intermedio del puente de compañías de televisión por suscripción } \\
\text { DirecTV (Canal 93), Supercable (Canal 77), Intercable (Canal 93) y NetUno (con varios canales, visibles } \\
\text { en importantes ciudades del país). En Caracas se puede sintonizar por el Canal } 62 \text { de UHF. }\end{array}$ \\
\hline
\end{tabular}




\begin{tabular}{|c|c|}
\hline \multirow{10}{*}{ Televisión } & $\begin{array}{l}\text { - Fundación Televisora Venezolana Social (TVES): dio comienzo a sus operaciones el } 28 \text { de mayo de } \\
2007 \text { tras el retiro de la concesión a RCTV la noche del } 27 \text { de mayo de ese año, aunque su creación } \\
\text { había sido aprobada previamente ( } 14 \text { de mayo de 2007) por la vía de un decreto presidencial publicado } \\
\text { en la Gaceta Oficial N }{ }^{\circ} 38681 \text {. Entra en el espectro radioeléctrico bajo el lema de "televisión de servicio } \\
\text { público". Utiliza la red de cobertura que ya tenía instalada RCTV. }\end{array}$ \\
\hline & $\begin{array}{l}\text { - Alba TV: reviste un perfil internacional. Si bien su diseño vio la luz en } 2007 \text {, todavía no se ha materializado } \\
\text { como experiencia de "televisión comunitaria internacional". }\end{array}$ \\
\hline & $\begin{array}{l}\text { A este grupo conviene agregar una serie de canales estrenados entre } 2010 \text { y } 2014 \text {, en el marco de la llamada } \\
\text { "nueva televisión del Siglo XXI", alineada con la televisión digital abierta (TDA). }\end{array}$ \\
\hline & $\begin{array}{l}\text { - ConCienciaTv: canal temático dedicado a la difusión de la ciencia, la tecnología y la innovación. Es } \\
\text { el primer medio de comunicación diseñado, desde sus inicios, para la televisión digital abierta. Se } \\
\text { posiciona como "un espacio de divulgación científica que reivindica los saberes populares y su relación } \\
\text { con otras formas de producción del conocimiento, mostrando los distintos rostros de la ciencia y } \\
\text { generando contenidos que den cabida al disfrute de un tipo de formación liberadora, fundamentada en } \\
\text { la participación, la igualdad, la solidaridad y el reconocimiento de la innovación popular, más allá del } \\
\text { formato del entretenimiento" (http://concienciatv.gob.ve/). }\end{array}$ \\
\hline & $\begin{array}{l}\text { - Televisora de la Fuerza Armada Nacional Bolivariana (TV FANB): se traza como misión "Participar en } \\
\text { la pre-producción, producción y post-producción, difusión de contenidos audiovisuales que informen, } \\
\text { eduquen y recreen al ser Latinoamericano y Caribeño sobre hechos, conocimientos e historia nacional, } \\
\text { regional y global, que reflejen nuestra perspectiva y realidad, estimulen el sentido identidad, pertenencia } \\
\text { y el amor hacia la patria" (http://tvfanb.mil.ve/). }\end{array}$ \\
\hline & $\begin{array}{l}\text { - ZUM Televisión (ZUM TV): se define como la "televisora juvenil de Venezuela [...] la televisora } \\
\text { del futuro, de la Generación de Oro, de la Juventud de la Patria de Bolívar y Chávez" (https://twitter. } \\
\text { com/ZUMTV)). Su estructuración se encuentra a cargo del Ministerio para la Juventud. Plantea una } \\
\text { programación dedicada a la presentación de manifestaciones culturales, programas de salud, cine, música } \\
\text { y tradiciones venezolanas. }\end{array}$ \\
\hline & $\begin{array}{l}\text { - Petróleos de Venezuela S.A. Televisión (PDVSATV): primer canal de televisión orientado a la información } \\
\text { de la industria petrolera. "Nace de la necesidad de informar acerca de las operaciones de la principal } \\
\text { industria del pueblo venezolano y sus planes de inversión social, con los más altos estándares de calidad } \\
\text { técnica y audiovisual" (www.pdvsa.go.ve). Tiene canales asignados en TDA/TDT. Ofrece tres emisiones } \\
\text { diarias de una hora cada una, distribuidas en los siguientes horarios: de 7:00 a.m. a 8:00 a. m., de 12:00 m. } \\
\text { a 1:00 p. m.y de 7:00 p. m., a 8:00 p. m. Incluye espacios sobre política e historia del petróleo en Venezuela, } \\
\text { aparte de detalles acerca del Plan Siembra Petrolera. }\end{array}$ \\
\hline & $\begin{array}{l}\text { - Colombeia TV: ideada como "la televisora educativa de Venezuela", es un canal que produce contenidos } \\
\text { audiovisuales de tipo cultural e informativo, encaminados al crecimiento profesional, la formación } \\
\text { ciudadana y el desarrollo de valores humanos. Su nombre está inspirado en los archivos personales del } \\
\text { prócer venezolano Francisco de Miranda, quien escribió y organizó, entre los años } 1771 \text { y 1810, } 63 \\
\text { tomos para dejar constancia de sus acciones en pro de la independencia americana. Dispone de una } \\
\text { señal analógica en Caracas por el canal } 64 \text { UHF. }\end{array}$ \\
\hline & $\begin{array}{l}\text { - } 123 \mathrm{TV} \text { : primer canal recreativo y educativo del Estado venezolano, inscrito en un modelo de televisión } \\
\text { infantil "coherente con nuestro imaginario y pensamiento implícito en nuestra sociedad e identidad } \\
\text { como venezolanos". Dirigido a niños y niñas hasta los siete años de edad. Transmite las } 24 \text { horas a través } \\
\text { de Cantv televisión satelital. También puede verse por la frecuencia del canal VIVE TV, en su franja } \\
\text { infantil, de lunes a viernes, entre las 9:00 a.m., y las 3:00 p.m., y los sábados y domingos a las 8:30 a.m. }\end{array}$ \\
\hline & $\begin{array}{l}\text { Por lo pronto, el presidente Nicolás Maduro ha anunciado la próxima puesta a punto de TV Obrera y de } \\
\text { la Televisora Nacional de las Comunas (TV Comunas) -esta última puesta en primer plano en septiembre } \\
\text { de 2013-, en aras de abrir un nicho para que los consejos comunales y comunidades organizadas puedan } \\
\text { compartir información relevante sobre su trabajo, experiencias y vida cotidiana. }\end{array}$ \\
\hline
\end{tabular}




\begin{tabular}{|c|l|}
\hline \multirow{1}{*}{ - Circuito Radio Nacional de Venezuela (RNV): muestra una expansión en amplitud modulada: RNV } \\
Canal Informativo, RNV Canal Clásico, RNV Canal Musical, RNV Canal Indígena, RNV Canal Juvenil \\
-Activa, RNV Canales Regionales -Central, Los Llanos, Portuguesa y RNV Canal Internacional. Este \\
plan de expansión se efectuó paralelamente a la restructuración de la emisora, establecida por el decreto \\
presidencial número 3.597, publicado en la Gaceta Oficial 38.164 con fecha del 12 de abril de 2005. Tiene \\
entre sus haberes un servicio informativo en onda corta que cubre una buena parte del continente, \\
incluyendo Centroamérica, el Caribe y Estados Unidos.
\end{tabular}

Fuente: elaboración propia a partir de Bisbal (2012, pp. 9 y ss.).

calidades poco atractivas para la inversión privada. Asimismo, desde el 29 de octubre de 2008 gravita en el espacio el Satélite Simón Bolívar, conocido internacionalmente como Venesat 1, administrado por el Ministerio del Poder Popular para la Ciencia y la Tecnología a través de la Agencia Bolivariana para Actividades Espaciales ( $\mathrm{ABAE}$ ) de Venezuela; su objetivo último es satisfacer, mediante la colocación de puntos de conexión, las necesidades nacionales de acceso y transmisión de datos por Internet, amén de servicios de telefonía, televisión, telemedicina y teleeducación, sobre todo en los lugares más remotos del país, con poca densidad poblacional. Como complemento, en 2012 se puso en órbita el Satélite Francisco de Miranda para observación remota (Bisbal, 2013, p. 61).

En estas lides, preciso es subrayar el tendido del cable submarino La Guaira/Siboney de $640 \mathrm{~Gb}$ (gigabytes), el cual forma parte del proyecto Sistema Internacional de Telecomunicaciones ALBA 1, cuyo costo ascen- 
dió a 70 millones de dólares, reservándose su administración a Telecomunicaciones Gran Caribe, empresa compartida en propiedad por Venezuela (60\% por conducto de Telecom Venezuela) y Cuba ( $40 \%$ gracias a Transbit).

De colofón, y en la onda de concluir este apartado, otra arista a resaltar por lo que concierne al área de las telecomunicaciones remite a la renacionalización, en enero de 2007, de la Compañía Anónima Teléfonos de Venezuela (Cantv) empresa pública hasta 1991, año en el que fue privatizada a favor de Verizon Communications, lo que supone el control del Estado sobre la telefonía fija, móvil y de Internet, transporte de voz, de datos y de video. Esto lo convierte en operador, aparte de regulador, con una concentración de influencias que abarca en su halo al Ministerio del Poder Popular para las Obras Públicas y Vivienda, el Instituto Postal Telegráfico de Venezuela (Ipostel), el Centro Nacional de Tecnología de la Información (CNTI) y la red de Transmisiones de Venezuela (Redtv) (Bisbal, 2014, p. 89).

\section{Cuadro de los medios de comunicación comunitarios}

Aun cuando desde la década de los ochenta el núcleo de la Universidad Simón Rodríguez y la Biblioteca Aquiles Nazoa en Caricuao apuntalaban iniciativas en pro de constituir una televisora comunitaria, sin desdeñar el hecho de que Radio Catia Libre 93.5 FM dio inicio a sus operaciones en 1996 y fue emulada por Radio Alternativa, Radio Perola y Radio Activa La Vega en 1998, las experiencias de comunicación alternativa en Venezuela guardaban un seño casi excepcional en la transición del viejo al nuevo siglo (Torrealba, 2009, p. 159).

Retomando los datos aportados por Llorente y Cuenca (2013, pp. 3-4), si bien es cierto que la tendencia a la concentración de la propiedad ha desembocado en el florecimiento de grupos gigantescos de comunicación como Televisa en México, O Globo en Brasil, Organización Diego Cisneros en Venezuela y Clarín en Argentina, no lo es menos que también ha decantado, por contrapartida, en el surgimiento de medios regionales y comunitarios que, salvando las distancias de un margen de acción más estrecho y una capacidad económica no muy holgada, han impulsado la escasa diversificación, repercutiendo a su vez sobre la movilización de colectivos locales. 
Volviendo la mirada hacia Venezuela, según fuentes oficiales acotadas por (Bisbal, 2013, p. 64) —Conatel, Minci y Asociación Nacional de Medios Comunitarios, Libres y Alternativos (Anmcla)—, para el momento hay en el país 400 medios del tercer sector de la comunicación, desagregados en 244 radios, 36 televisoras y unos 120 periódicos, beneficiarios de la partida presupuestaria del Minci, entidad que ha dedicado grandes esfuerzos a su fortalecimiento por intermedio de la Dirección de Medios Comunitarios y Alternativos de cara a la consolidación del Sistema Nacional de Medios Alternativos y Comunitarios. Así las cosas, apoyados en los Fondos de Servicio Universal y de Responsabilidad Social contemplados por la Ley Orgánica de Telecomunicaciones (Lotel), los medios comunitarios tienen acceso a subsidios para afrontar costos de infraestructura, así como también para el financiamiento de proyectos apalancados en el desarrollo en nuevas tecnologías, el fomento de la producción nacional, la capacitación a los productores nacionales y la educación a las comunidades para la recepción cívica de los mensajes (Gómez, 2013, p. 45).

Empero, estas prerrogativas también conllevan acciones de supervisión sobre los contenidos, toda vez que, con la entrada en vigencia del Reglamento de Radiodifusión Sonora y Televisión Abierta Comunitarias de Servicio Público, aprobado mediante el Decreto Presidencial 1521 del 03 de noviembre de 2001, Conatel, en calidad de órgano regulador, está facultada para hacer una evaluación periódica de las parrillas y los mensajes emitidos tanto por las estaciones radiofónicas como por las televisoras comunitarias, sugiriendo cambios en la programación y aplicando castigos cuando éstos no se acatan, acción que puede implicar la pérdida del reconocimiento como medio comunitario y su consiguiente desaparición. En esta misma tónica, se estipula un control sobre las personas que conforman los servicios de comunicación comunitaria, en el entendido de que, para la operación de este tipo de estaciones de radio y televisión, imperativo es que los interesados constituyan fundaciones comunitarias, demuestren la viabilidad económica y técnica del proyecto, y garanticen su sostenibilidad.

A título contradictorio, aunque la ley aboga por que los medios comunitarios sean "democráticos, plurales y participativos" (arts. 6 y 23), de la mano de unos contenidos que contribuyan a la solución de los proble- 
mas de la comunidad (art. 17), el reglamento repara en el deber de "encadenarse" a los medios de servicio público en determinados momentos y transmitir las alocuciones oficiales, lo que comporta deslastrarse de uno de los atributos esenciales de su condición: el carácter alternativo e incluyente. Para más, la normativa no incorpora mecanismos expeditos para evitar la dependencia financiera con respecto a los entes gubernamentales.

Vistos así, un diagnóstico preliminar sobre el desempeño de estos medios, calificados de "para-públicos" o "para-estatales", cuando no tachados de expresión política-ideológica en la "construcción de la patria socialista", pone de relieve cuatro asuntos críticos: 1) la agrupación de estos medios en el Sistema Nacional de Comunicación Popular, Alternativa y Comunitaria encarna una forma de vinculación directa con el Poder Ejecutivo Nacional, lo que afecta su necesaria pluralidad e independencia; 2) el sesgo político que prevalece en muchos operadores corrobora su abierta identificación como defensores del proyecto político que lideraba el presidente Hugo Chávez; 3) el retraso recurrente por parte de la Comisión Nacional de Telecomunicaciones para el otorgamiento o la renovación de las licencias trae implícito un talante punitivo, y 4) el reglamento acoge en su seno restricciones con relación al financiamiento de estos medios (Torrealba, 2013, p. 162).

En últimas, el crecimiento desordenado y desorientado de los medios alternativos-comunitarios, y su instrumentalización ideológica y propagandística, soslaya el poder democratizador que sus comunicaciones han de albergar.

\section{A modo de cierre}

En palabras de Becerra (2014, p. 62), "el modo en que se regula el sector de los medios es un indicador de peso para analizar la configuración del espacio público que se proyecta desde el Estado”. Al hilo de este planteo, y de acuerdo con los datos expuestos en las páginas precedentes, la política pública de comunicación implementada por el gobierno de Hugo Chávez, qué duda cabe, generó una metamorfosis en la estructura de los medios de comunicación en Venezuela, haciendo crecer el número de actores, su va- 
riedad y las características de la propiedad. En este enclave, la magnitud del sector público se ha dilatado, incrementando su poder mediático hasta erigirse en el segundo grupo de comunicaciones más grande del país a juzgar por el número de unidades radiofónicas y televisivas que posee, entre las que cabe incluir a los medios alternativos-comunitarios.

Este último aspecto para nada resulta baladí si se analiza a la luz del argumento expuesto por Mastrini y Becerra (2007, pp. 18-19), refrendado por Hernández y Reina (2010, p. 29), para quienes la pluralidad de medios de expresión pública, aparejada a la ampliación de los espacios para la participación, no reviste, por sí sola, condición suficiente para garantizar un cambio de conciencia y de prácticas mediáticas. Antes bien, reclama de parte del Estado trascender la esfera meramente legal e instrumental para asegurar, junto a la multiplicidad de contenidos, el genuino reflejo de las identidades de diferentes actores, en diferentes temporalidades y lugares, y en distintos contextos socioeconómicos.

A lo largo de sus catorce años de gestión gubernativa, Hugo Chávez fue enfático en la necesidad de dotar a Venezuela de un "nuevo orden comunicacional" de cuño socialista, que fue consustancial a su proyecto político. Desde esta perspectiva, el ímpetu del Estado comunicador fue efectivo en la medida en que desaceleró el otorgamiento de concesiones a grandes conglomerados y atenazó su radio de acción y capacidad de respuesta; sin embargo, fracasó estrepitosamente a la hora de ensanchar los públicos de los nuevos medios estatales, percibidos cual dispositivos de propaganda gubernamental. Nomás, como muestra, según los datos arrojados por la empresa de investigación Obitel Venezuela, para el año 2012 el índice de audiencia de las televisoras públicas fue insignificante: $\operatorname{ANTV}(0,03 \%), \mathrm{Te}-$ lesur (1,7\%), TVES (2\%), Vive TV (0,06\%) y VTV (5,63\%) (Quiñones, Bisbal y Aguirre, 2012, p. 39).

En consecuencia, pese a las transformaciones estructurales, sería válido aseverar que la concentración de la propiedad en estos años no se redujo en mayor cuantía, derivando los públicos desinteresados en los medios estatales hacia los medios de pago, o manteniéndose aferrados a los medios privados 
que transmiten en abierto. No por casualidad, pues, el Grupo Cisneros sigue ocupando el liderazgo en cuanto el volumen de los medios radioeléctricos, a expensas de la desaparición de su principal competidor en audiencia y ganancias por publicidad: Radio Caracas Televisión (RCTV).

De suyo, en tanto grupo de medios, el Estado venezolano se ha hecho con un sitial de envergadura en el entramado mediático, aunque el valor económico de ese conglomerado público y su verdadera contribución a la democratización de las comunicaciones está lejos de estimarse, permaneciendo velado detrás de una lógica política rematada por consideraciones de secreto de seguridad nacional.

\section{Referencias}

Becerra, M. (2014). Medios de comunicación: América Latina a contramano. Nueva Sociedad, 249, 61-74.

Bisbal, M. (2014). Medios de Comunicación Social en Venezuela —notas sobre nuestro escenario comunicativo- - En Anda-Fevap (ed.). Inversión Publicitaria en Venezuela 2013 (pp. 78-96). Caracas: Anda-Fevap.

Bisbal, M. (2013). Un nuevo régimen comunicativo. Política, poder y comunicaciones en tiempos de Chávez. En Bisbal, M. (ed.). Saldo en rojo. Comunicaciones y cultura en la era bolivariana (pp. 49-67). Caracas: Universidad Católica Andrés Bello (UCAB) - Konrad Adenauer Stiftung.

Bisbal, M. (2012). El Estado-comunicador y sus comunicaciones. ¿Comunicaciones de servicio público? Ponencia presentada en el I Encuentro de Organizaciones Sociales (EOS). Universidad Católica Andrés Bello (UCAB). Caracas, Venezuela.

Bisbal, M. (2009). La comunicación masiva como política del gobierno de Hugo Chávez Frías. En Bisbal, M. (coord.). Hegemonía y control comunicacional (pp. 23-60). Caracas: Editorial Alfa. 
Cañizález, A. (2013). Del cierre de RCTV a la venta de Globovisión. En Bisbal, M. (ed.). Saldo en rojo. Comunicaciones y cultura en la era bolivariana (pp. 178-192). Caracas: Universidad Católica Andrés Bello (UCAB) - Konrad Adenauer Stiftung.

Conde, J. (2014). Gerenciar desde la cerrazón de las fuentes oficiales. Intervención presentada en el Conversatorio SOS Venezuela: Libertad de Prensa y Derecho a la Información. Universidad de La Sabana. Bogotá, Colombia.

El Universal (2014, 5 de julio). El Universal inicia una nueva etapa. El Universal. Recuperado de: http://www.eluniversal.com/nacional-ypolitica/140705/el-universal-inicia-una-nueva-etapa.

Gómez, A. (2013). Venezuela entre el Estado comunicador y el pluralismo mediático (Trabajo inédito de fin de Máster). Instituto de Iberoamérica - Universidad de Salamanca, España.

Guzmán, C. y Quintero, Y. (2009). Tendencias del ecosistema comunicacional en Venezuela en tiempos de Chávez. Anuario Ininco. Investigaciones de la Comunicación, 22 (1), 173-185.

Guzmán, C. (2001). La industria publicitaria en Venezuela 1996-1999. Anuario Ininco. Investigaciones de la Comunicación, 1 (13), 215-252.

Hernández, D. y Reina, O. (2010). Elementos para la definición de una política de información y comunicación de Estado. En Sel, S. (coord.). Políticas de Comunicación en el capitalismo contemporáneo. América Latina y sus encrucijadas (pp. 17-38). Buenos Aires: Consejo Latinoamericano de Ciencias Sociales (Clacso).

Gaceta Oficial de la República Bolivariana de Venezuela 6118 Extraordinario (2013). Ley del Plan de la Patria. Segundo Plan Socialista de Desarrollo Económico y Social de la Nación 2013-2019. 
Llorente y Cuenca (2013). Panorama audiovisual en América Latina. Concentración y renovación tecnológica (informe especial). España: Llorente y Cuenca.

Mastrini, G. y Becerra, M. (2007). Presente y tendencias de la concentración de medios en América Latina. Zer, 22, 15-40.

Minci (2007). Plan Nacional de Desarrollo Económico y Social 2007-2013. Caracas: Minci.

Pellegrino, F. (2010). La economía de la comunicación en América Latina. En Bisbal, M.y Aguirre, J. (coords.). Prácticas y travesías de comunicación en América Latina (pp.37-58). Caracas: Fundación Centro Gumilla.

Presidencia de la República Bolivariana de Venezuela (2004). La Nueva Etapa, el Nuevo Mapa Estratégico. Caracas: Presidencia de la República Bolivariana de Venezuela.

Quiñones, R., Bisbal, M. y Aguirre, J. (2012). Los medios de comunicación social en Venezuela: de los medios a las redes. Caracas: Fundación Centro Gumilla - Universidad Católica Andrés Bello (UCAB).

Rey, J. (1989). El futuro de la democracia en Venezuela. Caracas: Instituto Internacional de Estudios Avanzados (IDEA).

Torrealba, L. (2013). De las garantías jurídicas a las restricciones legales en el gobierno de Hugo Chávez. En Bisbal, M. (ed.). Saldo en rojo. Comunicaciones y cultura en la era bolivariana (pp. 156-177). Caracas: Universidad Católica Andrés Bello (UCAB) - Konrad Adenauer Stiftung.

Torrealba, M. (2009). Estructura y funcionamiento del sistema mediático de Venezuela en datos. Anuario Ininco. Investigaciones de la comunicación, 21 (2), 147-171.

Weffer, L. (8 de enero de 2007). El socialismo necesita una hegemonía comunicacional. El Nacional, Cuerpo A, p. 4. 